\title{
Analytic Technique for Assessment of RNAi by Similarity
}

National Cancer Institute

\section{Source}

National Cancer Institute. Analytic Technique for Assessment of RNAi by Similarity. NCI

Thesaurus. Code C123896.

A computational method designed to analyze phenotypic readouts from multiple-sample RNAi screens in which each gene is targeted by multiple RNAi reagents. AT ARiS takes advantage of patterns in RNAi data across multiple samples in order to enrich for RNAi reagents whose phenotypic effects relate to suppression of their intended targets. By summarizing only such reagent effects for each gene, AT ARiS produces quantitative, gene-level phenotype values, which provide a measure of the effect of gene suppression in each sample. 